\title{
APPLICATION OF LAGGING VILLAGE MAPPING AND PRE- PROSPEROUS FAMILY USING BACK PROPAGATION ALGORITHM IN BATHIN III ULU DISTRICT BUNGO DISTRICT JAMBI PROVINCE Pariyadi $^{1)}$, Degita Astari Prakasiwi ${ }^{2}$ \\ ${ }^{1}$ Program Studi Teknik Informatika, STMIK Nurdin Hamzah Jambi \\ ${ }^{2}$ Program Studi Sistem Informasi, STMIK Nurdin Hamzah Jambi \\ Jl. Kolonel Abunjani, Sipin, Kota Jambi \\ Email : pariyadi@stmiknh.ac.id
}

\begin{abstract}
Lagging villages are areas that are generally located in districts that are relatively underdeveloped and have relatively underdeveloped populations compared to other regions on a national scale. Batin III Ulu District Bungo has 9 (nine) villages which have promising space potential including abundant forest resources, natural tourism, agricultural land and plantations. Village development has not yet had an optimal impact and there are still disadvantaged families in each village in Bathin III Ulu Subdistrict. Development of application mapping of disadvantaged villages and underprivileged families in Bathin III Ulu Subdistrict, Bungo District, Jambi Province is a qualitative research that aims to support the government in accelerating the implementation of services for underdeveloped villages and underprivileged families. Automated learning stage to determine mapping of disadvantaged villages and underprivileged families through the application of Artificial Neural Network $(A N N)$ as an adaptive system to model complex relationships between input and output to find patterns in the data and collaboration with Leaflet.Js as a library used for making thematic spatial maps that can emphasize priority objects to be addressed immediately. The application is built on a web-based basis so that users can easily access it anywhere and anytime as a reference in determining future development policies.
\end{abstract}

Keyword: Artificial Neural Network, Backpropagation, Mapping, Leaflet.js, underdeveloped village

Abstrak

Desa tertinggal merupakan daerah yang umumnya berada di kabupaten yang relatif kurang berkembang serta berpenduduk relatif tertinggal dibandingkan dengan daerah lain dalam skala nasional. Kecamatan Batin III Ulu Kabupaten Bungo memiliki 9 (sembilan) desa yang memiliki potensi ruang yang menjanjikan diantaranya melimpahnya sumberdaya hutan, wisata alam, lahan pertanian dan perkebunan. Pembangunan desa belum berdampak secara optimal serta masih terdapat keluarga prasejahtera di setiap desa pada Kecamatan Bathin III Ulu. Pembangunan aplikasi pemetaan desa tertinggal dan keluarga prasejahtera pada Kecamatan Bathin III Ulu Kabupaten Bungo Provinsi Jambi merupakan penelitian kualitatif yang bertujuan untuk mendukung pemerintah mempercepat pelaksanaan layanan perubahan desa tertinggal dan keluarga prasejahtera. Tahap pembelajaran yang terotomasi untuk menentukan pemetaan desa tertinggal dan keluarga prasejahtera melalui penerapan Artificial Neural Network (ANN) sebagai sistem adaptif untuk memodelkan hubungan yang kompleks antara input dan output hingga menemukan pola-pola pada data serta dengan kolaborasi Leaflet.Js sebagai library yang digunakan untuk pembuatan peta spasial tematik yang mampu menekankan objek prioritas untuk segera ditangani. Aplikasi dibangun dengan berbasis web 
agar para pengguna dengan mudah dapat mengakses dimanapun dan kapanpun sebagai salah satu referensi dalam menentukan kebijakan pembangunan di masa mendatang.

Kata kunci: Jaringan Syaraf Tiruan, Backpropagation, Pemetaan, Leaflet.js, Desa Tertinggal

\section{Pendahuluan}

Desa tertinggal adalah daerah kabupaten yang relatif kurang berkembang dibandingkan dengan daerah lain dalam skala nasional, dan berpenduduk yang relatif tertinggal. Desa tertinggal umumnya terisolasi dari pusat pertumbuhan di daerah lain akibat tidak memiliki atau kekurangan sarana infrastruktur yang mengakibatkan terhambatnya pertumbuhan kawasan. Kecamatan Batin III Ulu Kabupaten Bungo memiliki 9 (sembilan) desa yaitu dusun Aur Cino, dusun Buat, dusun Karak Apung, dusun Laman Panjang, dusun Lubuk Beringin, dusun Muara Buat, dusun Senamat Ulu, dusun Sungai Telang dan dusun Timbolasi yang semuanya memiliki potensi ruang yang menjanjikan di masa mendatang. Pembangunan desa yang dilakukan pemerintah setempat saat ini belum berdampak secara optimal, salah satu alasannya dikarenakan masih terdapat banyak pekerjaan rumah, utamanya jumlah keluarga prasejahtera hingga sebesar 21,5\% dari jumlah keluarga di Kecamatan Bathin III Ulu Kabupaten Bungo. Pembangunan aplikasi pemetaan desa tertinggal dan keluarga prasejahtera pada Kecamatan Bathin III Ulu Kabupaten Bungo Provinsi Jambi merupakan penelitian kualitatif yang bertujuan untuk mendukung pemerintah mempercepat pelaksanaan layanan perubahan desa tertinggal dan keluarga prasejahtera, tersajinya keluaran dari aplikasi yang berhasil diproses secara otomatis meliputi kompleksitas antara input dan output hingga diperoleh pola-pola data yang menunjukkan kawasan tertinggal serta keluarga prasejahtera serta mampu membuat aplikasi yang menerapkan Artificial Neural Network (Jaringan Syaraf Tiruan) dikolaborasikan dengan library Leaflet.js untuk membantu pemerintah daerah dalam proses manajemen maupun integrasi data. Pada penelitian lainnya seperti aplikasi pencarian rumah ibadah di Kotamadya Yogyakarta maupun sistem pencarian lokasi anjungan tunai mandiri (ATM) yang memiliki fasilitas Global Positioning System (GPS) serta pencarian obat apotek terdekat dengan memanfaatkan Google Map. Seluruhnya menggunakan pemanfaatan direction API pada layanan Google Map yang memiliki ketergantungan terhadap koneksi internet, berbeda bila antarmuka peta yang memanfaatkan library Leaflet.js tanpa perlu ketergantungan dengan koneksi internet dalam menampilkan antarmuka peta. Sehingga hal tersebut juga yang menjadi alasan dipilihnya penggunaan Leaflet.js yang diharapkan mampu diterapkan pada daerah pedesaan yang masih minim infrastruktur jaringan internet.

Dalam artikel yang berjudul "Pembuatan Virtual Guide Kabupaten Trenggalek Menggunakan Metode Tracing Map" menjelaskan bahwa diperlukan langkah untuk mendesain ulang peta dan melakukan riset kembali sehingga diharapkan mampu menggali dan merancang suatu peta dengan penyajian yang baru dan berbeda. Dari penjelasan tersebut terlihat bahwa penyajian peta terhadap informasi yang bersifat tematik yang juga dikuatkan pada penjelasan artikel berjudul "Rancang Bangun Sistem Informasi Obyek Wisata Berbasis Web menggunakan Metode User Centered Design (UCD)" bahwa pengguna (user) sebagai pusat dari proses pengembangan sistem. Maka pengembangan aplikasi peta selalu memerlukan beragam inovasi termasuk dalam hal otomasi, tahap pembelajaran pada aplikasi pemetaan ini juga dilakukan secara terotomasi untuk menentukan pemetaan desa tertinggal dan keluarga prasejahtera melalui penerapan Artificial Neural Network (Jaringan Syaraf Tiruan) sebagai sistem adaptif untuk memodelkan hubungan yang kompleks antara input dan output hingga menemukan pola-pola pada data. Dengan kolaborasi Leaflet.Js sebagai library yang digunakan untuk pembuatan peta spasial tematik diharapkan mampu menekankan objek 
prioritas untuk segera ditangani. Penelitian inipun mengacu pada beberapa peraturan antara lain :

- Peraturan Menteri Desa, Pembangunan Daerah Tertinggal, Dan Transmigrasi No 5 Tahun 2016 Tentang Pembangunan Kawasan Perdesaan

- Peraturan Menteri Desa, Pembangunan Daerah Tertinggal, Dan Transmigrasi No 4 Tahun 2017 Tentang Perubahan Atas Peraturan Menteri Desa, Pembangunan Daerah Tertinggal Dan Transmigrasi No 22 Tahun 2016 Tentang Penetapan Prioritas Penggunaan Dana Desa Tahun 2017

- Peraturan Menteri Dalam Negeri No 114 Tahun 2014 Tentang Pedoman Pembangunan Desa

\section{Metodologi Penelitian}

Metodologi penelitian sangat menentukan keberhasilan dalam melakukan suatu penelitian, karena dengan adanya metodologi penelitian penyelesaian masalah dapat dilakukan secara bertahap dan terstruktur. Kasus pada penelitian ini, untuk memetakan desa tertinggal dan keluarga pra sejahtera pada kecamatan Bathin III Ulu kabupaten Bungo Provinsi Jambi.

\subsection{Artificial Neural Network}

Artificial Neural Network (Jaringan Syaraf Tiruan) adalah sistem pemroses informasi yang memiliki karakteristik mirip dengan jaringan syaraf biologi. Jaringan syaraf tiruan sebagai generalisasi model matematika dari jaringan syaraf biologi, dengan asumsi bahwa :

- Pemrosesan informasi terjadi pada banyak elemen sederhana (neuron)

- Sinyal dikirimkan diantara neuron-neuron melalui penghubung-penghubung

- Penghubung antar neuron memiliki bobot yang akan memperkuat atau memperlemah sinyal

- Untuk menentukan output, setiap neuron menggunakan fungsi aktivasi (biasanya bukan fungsi linear) yang dikenakan pada jumlahan input yang diterima. Besarnya output ini selanjutnya dibandingkan dengan suatu batas ambang.

Jaringan syaraf tiruan sederhana pertama kali diperkenalkan oleh McCulloch dan Pitts di tahun 1943. McCulloch dan Pitts menyimpulkan bahwa kombinasi beberapa neuron sederhana menjadi sebuah sistem neural akan meningkatkan kemampuan komputasinya. Bobot dalam jaringan yang diusulkan oleh McCulloch dan Pitts diatus untuk melakukan fungsi logika sederhana. Fungsi aktivasi yang dipakai adalah fungsi threshold.

\subsection{Leaflet.Js}

Leaflet.Js (www.leafletjs.com) adalah open-source javascript library untuk membuat interactive maps. Library ini sangat populer karena mobile friendly, mempunyai ukuran file yang kecil dan dapat diextend dengan plugins ataupun dengan menggunakan fungsi javascript saja. Leaflet.Js dapat menampilkan peta/map dari berbagai sumber, seperti Google map, OpenStreetmap, OpenWheatherMap, dan lain-lain. Di penjelasan lain Leaflet JavaScript atau di singkat (LaefletJS) dijelaskan merupakan perpustakaan JavaScript yang bersifat Open Source. LeafletJS pertama kali dirilis oleh Vladimir Agafonkin pada tahun 2011. Library ini khusus digunakan untuk membangun aplikasi pemetaan berbasis web, memdukung sebagian besar mobile dan desktop platform. Leaflet biasa digunakan untuk membuat peta interaktif. Leaflet memiliki keunggulan yang lebih responsif jika dibandingkan dengan webgis karena data yang digunakan dengan format GeoJson. Script leaflet dapat di download secara gratis karena merupakan open source JavaSript Library dengan format js dan css. Bagi yang sudah 
mengenal HTML, CSS dan JavaScript mungkin tidak mengalami banyak kesulitan dalam membuat peta menggunakan Leaflet, namum bukan berarti bagi anda yang awam dengan coding tersebut mengalami kesulitan karena terdapat tutorial yang sangat mudah untuk dipelajari. Keuntungan lain menggunakan Leaflet terdapat beberapa Plugin yang dapat digunakan untuk "mempercantik" tampilan peta. Peta bukan hanya sebagai informasi atau sebagai analisis berbagai fenomena di atas permukanaan bumi (geografi), tetapi juga merupakan sebuah seni.

\section{Hasil dan Pembahasan}

Adapun implementasi pada antarmuka aplikasi pemetaan desa tertinggal dan keluarga pra sejahtera tersebut diantaranya adalah antarmuka halaman login, halaman admin, halaman data desa, halaman pengolahan data kepala keluarga, halaman peta desa dan keluarga, dan halaman rekapitulasi data berupa informasi grafik. Hasil Implementasi Aplikasi pemetaan desa tertinggal dan keluarga pra sejahtera berbasis Web ini menggunakan bahasa pemrograman PHP, framework codeigniter, framewrok bootstrap, serta library untuk antarmuka peta yaitu leaflet.js.

\subsection{Tampilan Halaman Login}

Halaman ini merupakan salah satu gerbang keamanan pada sistem ini, setiap pengguna diwajibkan untuk melakukan proses login yang terdiri dari kombinasi username dan password seperti terlihat pada gambar 1.

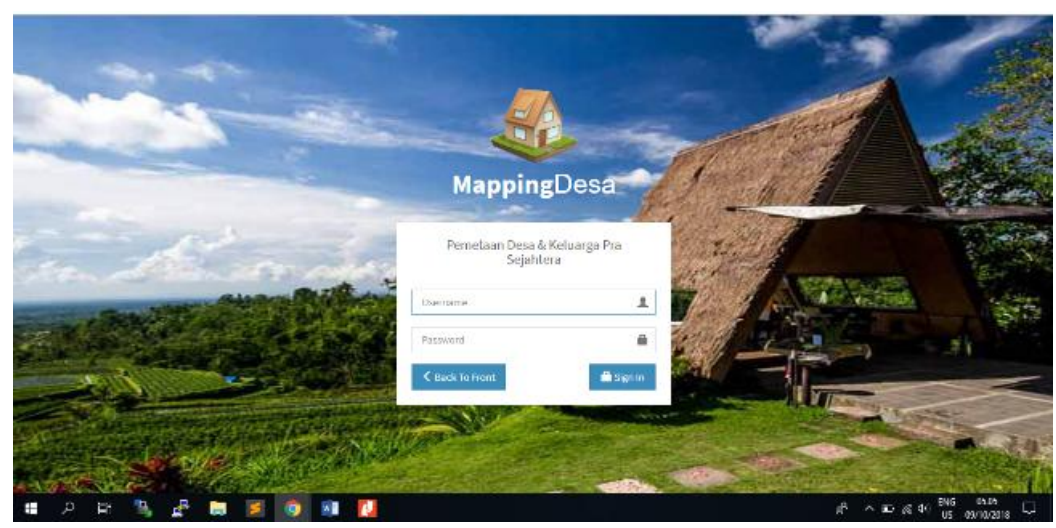

Gambar 1. Tampilan Form Login

\subsection{Tampilan Halaman Dashboard}

Tampilan halaman ini merupakan halaman yang pertama kali dilihat oleh pengguna ketika telah berhasil melakukan proses login. Halaman dashboard memuat informasi maupun statistic umum mengenai perkembangan data dan aplikasi. Halaman ini dapat dilihat di gambar 2. 


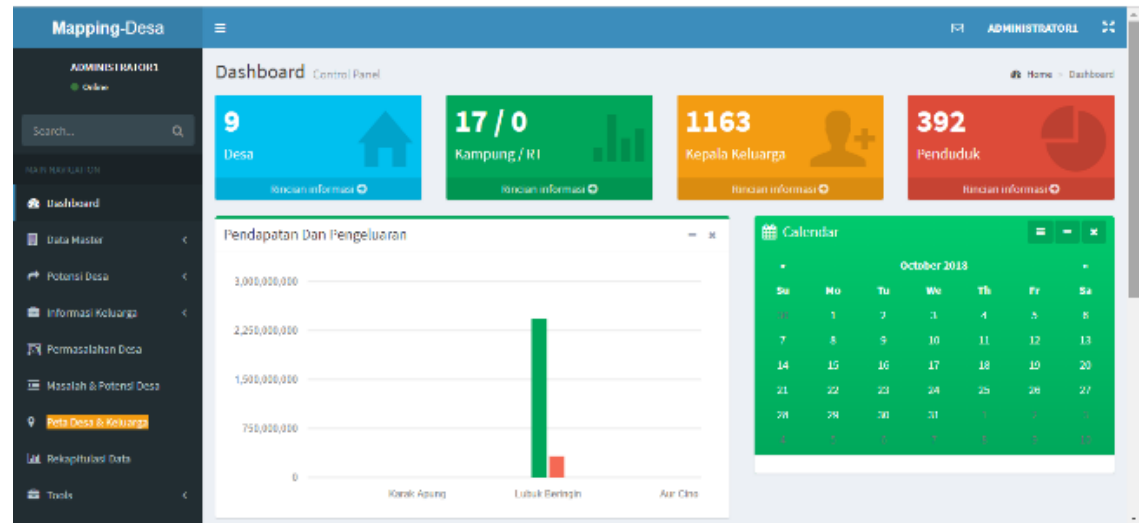

Gambar 2. Tampilan Halaman Dashboard

\subsection{Tampilan Halaman Pengolahan Data Desa}

Halaman ini merupakan halaman yang berfungsi sebagai pengolahan data desa, mulai dari fasilitas penginputan data, mengubah, menghapus maupun memilih dan mencari data desa. Tampilan pada halaman ini terlihat pada gambar 3 .

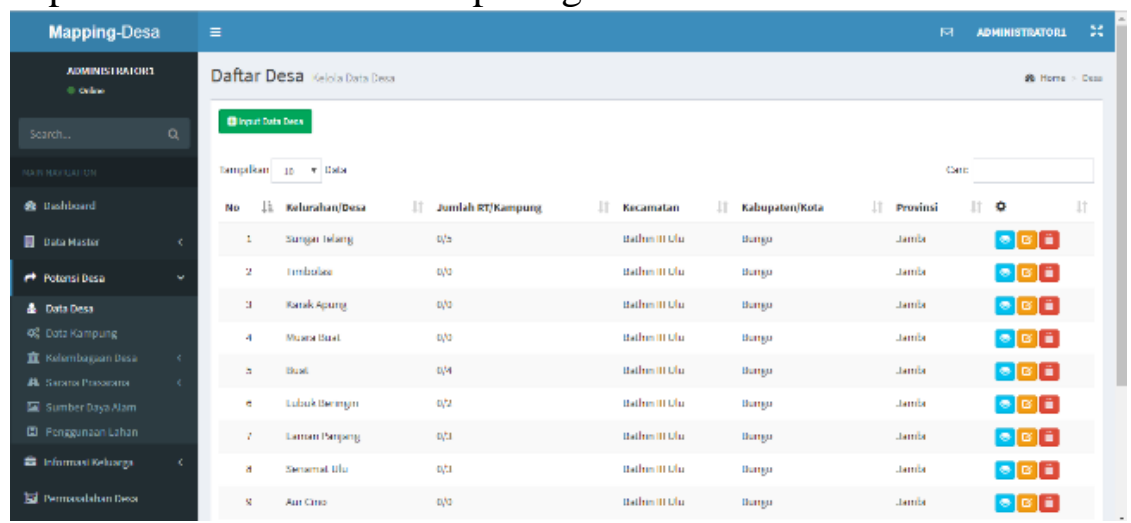

Gambar 3. Tampilan Halaman Pengolahan Data Desa

\subsection{Tampilan Halaman Pengolahan Data Kepala Keluarga}

Halaman ini merupakan halaman yang berfungsi sebagai pengolahan data kepala keluarga, mulai dari fasilitas penginputan data, mengubah, menghapus maupun memilih dan mencari data kepala keluarga. Tampilan pada halaman ini terlihat pada gambar 4.

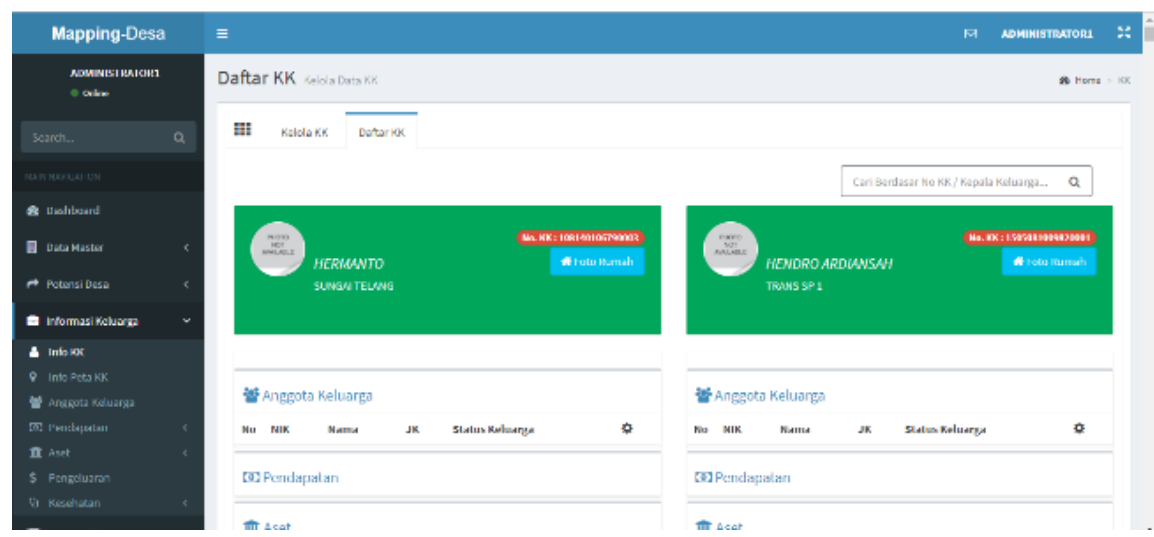

Gambar 4. Tampilan Halaman Pengolahan Data Kepala Keluarga 


\subsection{Tampilan Halaman Peta Desa dan Kepala Keluarga}

Halaman ini menyajikan peta dari desa dan kepala keluarga. Pada peta terdapat penanda (marker) yang memunculkan informasi rinci dari tampilan kawasan desa dan kepala keluarga seperti terlihat pada gambar 5 .

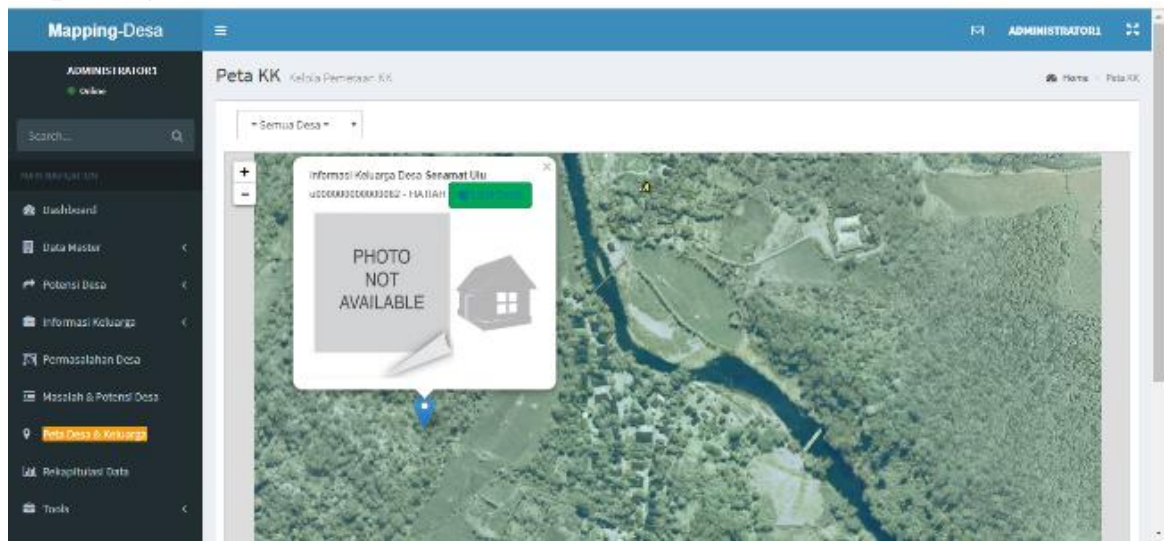

Gambar 5. Tampilan Halaman Peta Desa dan Kepala Keluarga

\subsection{Tampilan Halaman Rekapitulasi Data Berupa Informasi Grafik}

Halaman ini merupakan halaman rekapitulasi dari data yang berhasil terhimpun dan disajikan melalui informasi grafik sehingga mampu memperlihatkan statistik perbandingan maupun perkembangan data valid yang memiliki korelasi terhadap keadaan desa dan keluarga seperti terlihat pada gambar 6.
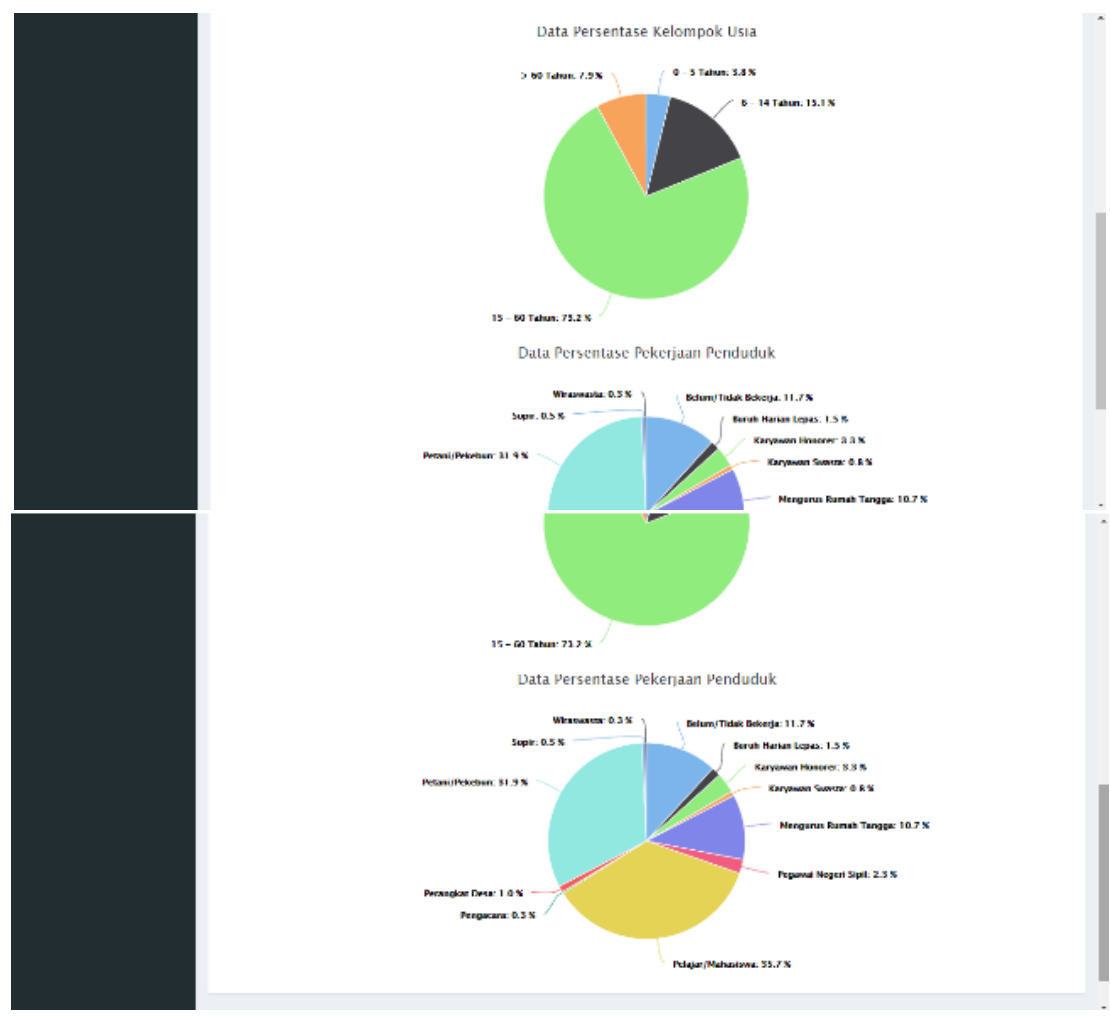

Gambar 6. Tampilan Halaman Rekapitulasi Data Berupa Informasi Grafik 


\section{Kesimpulan}

Dari hasil pengujian dari sistem yang dibangun pada penelitian ini dapat diambil beberapa kesimpulan sebagai berikut :

1. Penerapan jaringan syaraf tiruan (artificial neural network) dengan metode Backpropagation mampu untuk memetakan desa tertinggal dengan menggunakan kriteria ekonomi, sumber daya manusia, infrastruktur, kapasitas daerah, aksebilitas, serta karakteristik daerah dan memetakan keluarga pra sejahtera dengan kriteria ekonomi, pendidikan, kesehatan, dan tempat tinggal.

2. Dengan adanya aplikasi pemetaan desa tertinggal dan keluarga pra sejahtera ini diharapkan dapat membantu pihak terkait untuk mengevaluasi program kerja dan menentukan kebijakan prioritas pembangunan pada sebuah desa di masa mendatang.

Penulis sangat menyadari masih banyak terdapat kekurangan dalam aplikasi pemetaan desa tertinggal dan keluarga pra sejahtera yang telah dibuat. Untuk itu dalam kesempatan ini dapat dijabarkan beberapa saran untuk perbaikan dimasa mendatang. Diharapkan kepada penulis berikutnya agar memberikan penambahan fitur-fitur yang belum dipenuhi untuk lebih melengkapi penulisan ini, maka penulis dapat memberikan saran sebagai berikut :

1. Diharapkan dalam pengembangan aplikasi pemetaan, peneliti memahami penggunaan perangkat lunak berbasis geographic information system (GIS).

2. Dalam penerapan jaringan syaraf tiruan untuk pemetaan desa tertinggal dan keluarga pra sejahtera, peneliti selanjutnya dapat membangun aplikasi berbasis mobile seperti android maupun IOS.

\section{Ucapan Terimakasih}

Riset penulis dibayai oleh Hibah Penelitian Dosen Pemula Tahun Pelaksanaan 2018 dari DRPM Kemenristekdikti dengan kontrak No : 037/K10/KM/KONTRAKPENELITIAN/2018 Tanggal 12 Februari 2018.

\section{Daftar Pustaka}

[1] Badan Pusat Statistik Kabupaten Bungo Provinsi Jambi, Kecamatan Bathin III Ulu Dalam Angka, Tahun 2016

[2] Center for International Forestry Research (2008). "Belajar dari Bungo, Mengelola Sumber Daya Alam di Era Desentralisasi." Bogor: Penerbit CIFOR.

[3] Pratama, H. K. (2011). "Analisis Perbandingan Perceptron dan Backpropagation pada Pengenalan Tanda Tangan”. Program Studi Teknik Informatika, Fakultas Sains dan Teknologi, Universitas Islam Negeri Syarif Hidayatullah Jakarta.

[4] Leaflet Javascript, http://www.info-geospasial.com/2016/04/leaflet-javascript.html, diakses pada tanggal 13 Juni 2017

[5] Paulus Setyo, http://www.paulussetyo.com/post/view/leafletjs-menggunakan-customimage-sebagai-map, diakses pada tanggal 12 Juni 2017

[6] Peta Interaktif Leaflet, http://rhapidgis.com/wp/peta-interaktif-leaflet/, diakses pada tanggal 13 Juni 2017

[7] Siang, J. J. (2005). Jaringan syaraf tiruan dan pemrogramannya menggunakan Matlab. Penerbit Andi, Yogyakarta.

[8] Wikipedia, Pengertian Jaringan Syaraf https://id.wikipedia.org/wiki/Jaringan_saraf_tiruan, diakses pada tanggal 10 Juni 2017 
[9] Addiwinoto, G., \& Nugraheny, D. (2012). Pemanfaatan Direction Api (Application Programming Interface) Pada Layanan Google Map Untuk Pencarian Rumah Ibadah Di Kotamadya YOGYAKARTA Pada Handphone Berbasis Android. Compiler, 1(2).

[10] Nurahmanto, H., Sumarsono, S., \& Suhayati, M. (2013). Sistem Pencarian Lokasi Anjungan Tunai Mandiri (ATM) Memanfaatkan Google Map Untuk Handphone Android Yang memiliki Fasilitas Global Positioning System (GPS) Studi Kasus BPD DIY. Compiler, 2(1).

[11] Prambudi, A. R., \& Retnowati, N. D. (2014). Pembuatan Virtual Tour Guide Kabupaten Trenggalek Menggunakan Metode Tracing Map. Compiler, 3(2).

[12] Anggriawan, D., \& Retnowati, N. D. (2014). Pencarian Obat Pada Apotek Terdekat Dengan Memanfaatkan Google Map. Compiler, 3(2).

[13] Azzami, W., Kusumaningrum, A., \& Sudaryanto, S. (2018). Pemanfaatan Geofence Untuk Mencari Lokasi Bengkel Tambal Ban Terdekat Berbasis Android. Compiler, $7(1)$.

[14] Yuliani, O., \& Prasojo, J. (2015). Rancang Bangun Sistem Informasi Obyek Wisata Berbasis Web Menggunakan Metode User Centered Design (Ucd). Angkasa: Jurnal Ilmiah Bidang Teknologi, 7(2), 149-164. 